\title{
REVUELTA Y RENACIMIENTO: UNA LECTURA COSMOLÓGICA DEL CARNAVAL TZOTZIL ${ }^{1}$
}

Kazuyasu OchiaI

Universidad de Chubu, Japón.

\section{ESTUDIOS ACERCA DEL CARNAVAL DE LOS ALTOS DE CHIAPAS}

En los últimos cuarenta años parece que el carnaval, por sus características exclusivas y espectaculares, ha llamado la atención de los antropólogos que han trabajado en los Altos de Chiapas. Por ejemplo, Calixta Guiteras Holmes, una de las primeras antropólogas en llevar a cabo trabajo de campo entre los tzotziles en la década de los cuarenta, dejó páginas de descripciones detalladas del carnaval de Chenalhó en sus notas de campo (Guiteras Holmes 1946). Ricardo Pozas dedicó una sección de su etnografía clásica de Chamula a esta fiesta especial (Pozas 1959:174-184). La fiesta de San Sebastián de Zinacantán, que contiene numerosos elementos carnavalescos, ha sido descrita en detalle y analizada por Evon Z . Vogt (Vogt 1969: 536-551; 1976a, 1976b: 159-178). Particular atención fue prestada por Gary H. Gossen al aspecto lingüístico del carnaval de Chamula (Gossen 1974: 138-139, 178-182). Recientemente el mismo carnaval de Chamula fue metódicamente filmado por Thor Anderson. En cuanto a los tzeltales, Andrés Medina contribuyó con un informe etnográfico del carnaval de Tenejapa (Medina 1965). Aurore Becquelin-Monod y Alain Breton estudiaron el

1 Este ensayo es una versión más amplia de la ponencia presentada bajo el mismo título en el congreso "Cuarer.ta Años de Investigaciones Antropológicas en Chiapas: Conmemoración", celebrado en San Cristóbal de Las Casas del 19 al 23 de julio de 1982 . 
carnaval de Bachajón (Becquelin-Monod \& Breton 1973, 1979) cuyo aspecto histórico fue analizado independientemente por Jan de Vos (de Vos 1979: 247-258). Todos estos trabajos reconocen los caracteres particulares del carnaval por los cuales la fiesta se destaca de las otras fiestas anuales. Pero es Victoria R. Bricker quien ha contribuido con el análisis más importante para entender las características únicas de los carnavales tzotziles (Bricker 1973, 1981). Como punto de partida de este ensayo, me parece apropiado revisar brevemente los argumentos principales de Bricker.

En su primer libro, Ritual Humor in Highland Chiapas (1973), Bricker interpreta el ambiente humorístico y la risa de los carnavales tzotziles como crítica social y refuerzo moral. Bricker extrae una serie de oposiciones binarias del simbolismo tzotzil e indica que mientras que los elementos en la columna de "lo bueno", tales como 'humano', 'razón', 'indio' y 'tierras altas', representan la vida diaria normativa de la comunidad; los elementos de la columna de "lo malo", tales como 'animal', 'impulso', 'ladino' y 'tierras bajas', aparecen durante el carnaval (Bricker 1973: 166). Bricker concluye que los carnavales tzotziles ponen de relieve la superioridad del comportamiento normativo de los miembros de la comunidad contrastándolo con el comportamiento anormal que se da durante el carnaval (Bricker 1973: 224). Esta teoría, por cierto, podría explicar algunos aspectos del carnaval. Sin embargo, me parece que Bricker no evalúa de manera suficiente la potencialidad de la risa carnavalesca tzotzil. Según he observado, en el carnaval tzotzil la gente no solamente se ríe de la conducta desviada, sino que se burla marcadamente del valor normativo mismo. En otras palabras, durante el carnaval el valor normativo tampoco puede ser tan absoluto como Bricker infiere, sino que se vuelve relativo (cf. Bakhtin 1967).

En su segundo libro, The Indian Christ, the Indian King (1981), Bricker muestra un gran avance en el acercamiento a los carnavales tzotziles en especial en cuanto a sus aspectos históricos. Señala que el tema central del carnaval es el conflicto étnico que está ritualizado durante el carnaval como un drama histórico. Dicho drama se representa en un patrón que está determinado por los numerosos disfrazados, tales como los Hombres Negros, los Monos con el uniforme de los soldados franceses del siglo pasado, los Lacandones, los Guatemaltecos, de mujeres, etc., cuyas imágenes surgen de diferentes épocas históricas (Bricker 1981: 130). Después del minucioso análisis iconográfico de los disfrazados, Bricker concluye que en el carnaval de Chamula se hallan dramatizados siete conflictos étnicos his- 
tóricos distintos: 1) la conquista de México incluyendo Chiapas; 2) la rebelión de Cancuc en $1712 ; 3$ ) la intervención francesa de $1862-1867$; 4) el levantamiento de los chamulas durante 1867-1870; 5) la disputa sobre la frontera con Guatemala en el siglo xxx;6) la insurrección pinedista de 1920 y 7) la pasión de Jesucristo (Bricker 1981: 135). También distingue siete conflictos étnicos históricos en el carnaval de Chenalhó (Bricker 1981: 135-136) y cinco en el carnaval de Zinacantán (Bricker 1981: 138).

Bricker dice que estos conflictos étnicos están tratados en el carnaval como si fueran uno solo (Bricker 1981: 135). Según ella, la tradición oral también trata a los líderes de varios conflictos étnicos como equivalentes e intercambiables (Bricker 1981: 149). Atribuye esta "confusión" a "la visión telescópica del tiempo" que la gente tiene. La gente no hace distinción alguna entre la cronología de los hechos y los agentes históricos; es como si las cosas remotas se vieran a través de un telescopio aunque en realidad haya distancia entre ellas. Bricker dice: "el tiempo está 'telescopiado' en el mito y en el ritual del conflicto étnico de Chamula, Zinacantán y Chenalhó, de tal modo, que hace posible simbolizar muchos eventos al mismo tiempo" (Bricker 1981: 150). En seguida, Bricker presenta una observación importante:

En la atemporalidad de la tradición oral y el ritual, no hay lugar para la individualidad. El héroe de un conflicto es héroe de todos los conflictos. Él puede ser referido con el nombre de todos los héroes o de cualquiera de ellos. El malvado que se opone al héroe puede tener el nombre de cualquier malvado de cualquier periodo (Bricker 1981: 150).

¿A qué se debe esta "distorsión temporal"? Bricker la atribuye a "la visión cíclica del tiempo" de los tzotziles, por la cual captan los acontecimientos históricos como si fuera la repetición de un solo tema. Naturalmente salta otra pregunta: ¿cuál es la base de "la visión cíclica del tiempo" que engendra el drama histórico condensado durante el carnaval? Bricker no da una respuesta clara, sino que dice que los mayas antiguos de Yucatán tenían la idea del ciclo de doscientos cincuenta y seis años (el ciclo katun), que les daba la visión fatalista; los tzotziles modernos han mantenido esta visión cíclica del tiempo en la escala del ciclo anual (Bricker 1981: 7-8). No estoy seguro, sin embargo, de que esta discusión de Bricker sea lo suficientemente convincente para probar que el drama histórico del carnaval tzotzil se deba a la idea del ciclo anual, aunque tal idea 


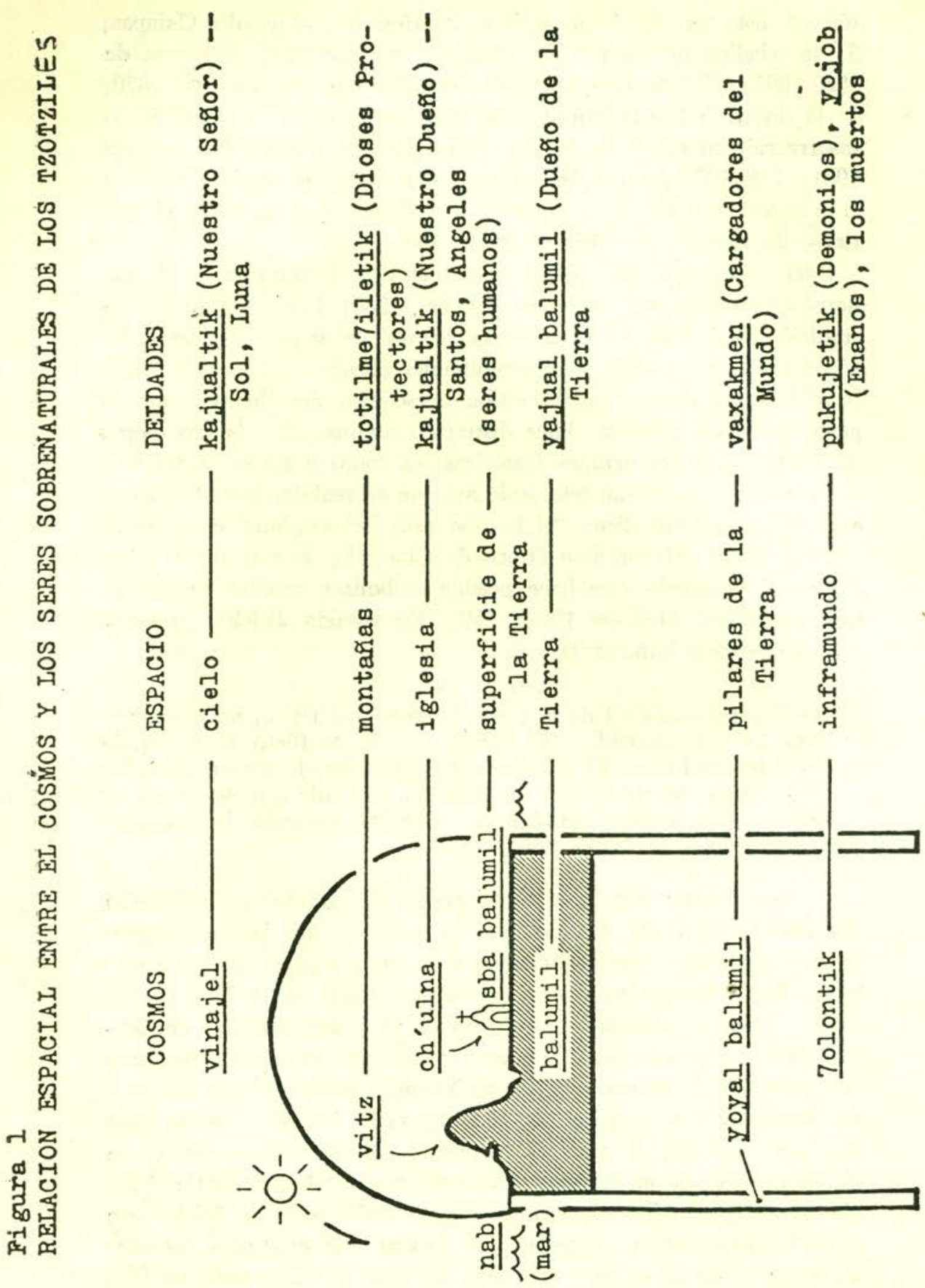


se observa, por cierto, entre los tzotziles. Creo que el concepto del ciclo anual no proporciona una base lógica al drama histórico del carnaval tzotzil como sugiere Bricker; tenemos que buscarla en otra parte y de otra manera.

La meta de este ensayo es tratar de aclarar la lógica del carnaval tzotzil. Siguiendo el ejemplo de Bricker, pienso partir del análisis de los personajes que los tzotziles comprimen y presentan como uno solo durante el carnaval. Bricker precisó las diferencias entre ellos; yo, en cambio, prestaré atención a sus características comunes. Mientras que Bricker las examinó minuciosamente desde el punto de vista histórico, yo intento analizarlas desde la perspectiva cosmológica. Para lograrlo, tendré que revisar brevemente la cosmología tzotzil.

\section{Cosmología tzotzil}

La cosmología tzotzil puede sintetizarse como lo muestra la Figura 1, aunque haya algunas variantes entre los pueblos tzotziles. ${ }^{2}$

El universo se compone de tres niveles básicos: cielo, tierra e inframundo. La capa superior es el cielo (vinajel ${ }^{s}$ ), que es un cubo de tres estratos (en Zinacantán [Vogt 1969: 297]) o de tres cúpulas concéntricas (en Chamula [Gossen 1974: 21]), con los cuerpos celestes en cada estrato o cúpula. El sol y la luna son las figuras centrales del cielo y del panteón tzotzil. Se llaman, respectivamente, Nuestro Padre (jtotik) y Nuestra Madre (jme7tik) y genéricamente Nuestro Dueño (kajualtik). Las imágenes católicas de las iglesias son consideradas como sus hermanas y se refieren con la misma denominación de Nuestro Padre o Nuestra Madre según su sexo. En el tiempo primordial, no había sol ni luna; sólo vivían los Demonios, Judíos y Monos en la oscuridad (Gossen 1974: 30-31; Guiteras Holmes 1961: 291; Holland 1963: 71). Aunque el poder de Nuestro Dueño sea infinito, puede ser aniquilado al igual que los seres humanos. Así que la gente tiene que intervenir, por medio de

2 Esta cosmografía tzotzil se manifiesta en forma visual cuando la gente construye las plataformas ceremoniales llamadas moch en Larráinzar o xmoch en Chamula (Ochiai y Sanmiguel 1981).

3 El tzotzil que aparece en este ensayo es el dialecto de Larráinzar, si no se anota otra cosa. Todas las palabras tzotziles se encuentran en bastardillas excepto las toponimias. El tzotzil aplica las consonantes glotalizadas y los cierres glotales que se indican, respectivamente, con $/$, y $17 \%$ 
rezos y ofrendas para prevenir el aniquilamiento del sol y la luna, lo cual podría causar la destrucción de la existencia humana (Guiteras Holmes 1961: 287, 291).

La tierra (balumil) es la capa intermedia de los tres estratos del universo. La describen como un cubo de forma cuadrangular o rectangular, como son las casas indígenas, sostenido por cuatro pilares de esquinas (yoyal balumil en Larráinzar; yokol balamil en Zinacantán [Vogt 1969: 297]), como los postes de las casas, rodeada por el mar (Gossen 1974: 18-22; Guiteras Holmes 1961: 285; Holmes 1961: 285; Holland 1963: 69; Vogt 1969: 297, 1976b: 13). Las deidades que están en las cuatro esquinas son los Cargadores del Mundo (vaxakmen) quienes llevan a la tierra sobre sus hombros. Cuando alguno de ellos se cansa y cambia su carga (la tierra) de un hombro al otro, ocurre un temblor que no cesa hasta que la carga se asegura de nuevo (Gossen 1974: 22; Holland 1963: 92; Vogt 1969: 303, 1976b: 13).

Las actividades cotidianas de la gente no se extienden más allá de la superficie de la tierra (sba balumil). Se considera que la cabecera de cada municipio se encuentra en el centro de la superficie de la tierra, o en "el ombligo de la tierra" (mixik balumil).

En las montañas prominentes viven los espíritus de los animales compañeros (vayjel en Larráinzar, chanul en Zinacantán y Chamula) amparados por los Dioses Protectores (totilme7iletik en Zinacantán [Vogt 1970: 1156] y Larráinzar) o por San Jerónimo (en Chamula [Gossen 1975: 450-451]).

Cualquier oquedad en la tierra, como un manantial o una cueva, es la entrada que sigue a la morada profunda del Dueño de la Tierra (yajual balumil).

El Dueño de la Tierra es un ser ambivalente. Es benévolo en el sentido de que proporciona a la gente los satisfactores de necesidades diarias tales como agua, leña, piedra y productos agrícolas; también es malévolo porque siempre trata de arrancar las almas de la gente y llevarlas a su morada adentro de la tierra con el fin de convertirlas en sus esclavas. Si un brujo da las suficientes ofrendas al Dueño de la Tierra, el primero recibirá un favor y torturará el alma de la víctima, que enfermará inevitablemente (Holland 1963: 94). El Dueño de la Tierra, al ser el dueño de la capa cósmica inmediata superior al inframundo, tiene continuidad con las características de los seres del inframundo.

Debajo de la tierra hay otra capa, el inframundo (7olontik en Larráinzar, 7olon balamil en Zinacantán [Vogt 1969: 298]), que está 
estrechamente ligado con la muerte y tiene muchas características opuestas al nivel terrestre. Como dice Gossen, cuando "reina la oscuridad sobre la tierra hay luz en el inframundo, pues el sol está recorriendo esa parte de su órbita circular alrededor de la tierra. A la inversa, es de noche en el inframundo cuando es de día sobre la tierra" (Gossen 1974: 21). Los habitantes del inframundo son los muertos, los Demonios (pukujetik) y los Enanos que se han quedado ahí desde el pasado remoto mitológico (yojob en Chenalhó [Guiteras Holmes 1961: 285]; konchavetik en Zinacantán [Vogt 1969: 298]). La presencia de los Demonios también se remonta al pasado mítico antes de que la cultura humana en su forma correcta apareciera bajo la protección de las deidades del cielo (Gossen 1974: 24, 233; Guiteras Holmes 1961: 57; cf. Holland 1963: 71). Los Demonios adquieren diversos aspectos antropomórficos y desean comerse las almas y la carne de la gente (Guiteras Holmes 1961: 179180; Holland 1963: 96, 124-130; Vogt 1969: 305). El más común y temido es el Hombre Negro $\left(j 7 i k^{\prime} a l\right)$; un hombre pequeño de tez oscura con pelo crespo y pies alados, que va vestido de ladino con pantalones negros, camisa, zapatos y sombrero. Al oscurecer, los Hombres Negros salen de la cueva volando como murciélagos y buscan comida, o sea, carne humana y animal (Blaffer 1972; Guiteras Holmes 1961: 189; Holland 1963: 125-127; Vogt 1969: 305).

Durante el día la gente es observada y protegida por el sol que es el origen de la luz y del calor, y los Demonios están confinados en el inframundo. En la noche, en cambio, el sol se ha puesto en el horizonte, y los Demonios salen del inframundo, vagabundean sobre la superficie de la tierra y atacan a la gente. Al amanecer, los Demonios regresan al inframundo a través de las cuevas, y los hombres son protegidos por el sol nuevamente. La humanidad está en peligro también durante los eclipses, ya que le falta la protección del sol y la luna. En Chenalhó dicen que los demonios ansían comerse al sol y a la luna durante los eclipses, de la misma manera que se roban y se comen a las almas humanas (Guiteras Holmes 1961: 174, 246; cf. Gossen 1974: 29-30). Guiteras Holmes concluye que la meta de los Demonios es la destrucción de los seres humanos y sus protectores, de modo que hay un conflicto constante en torno a la vida humana entre los Demonios y el sol (Guiteras Holmes 1961: 173, 292).

Una vez revisadas las categorías de los seres sobrenaturales tzotziles, éstos se pueden esquematizar en la Figura 2, que muestra las posiciones simétricas de los principios cosmológicos en cuanto a sus 
propios lugares y características, con la superficie terrenal como eje de tal simetría, la cual es una oposición de las polaridades estáticas. En la vida cotidiana, los principios positivos $(+)$ dan los valores centrales y normativos, y los principios negativos (-) se quedan en la periferia del sistema de valor. Sin embargo, cuando se traducen en términos dinámicos tales como narrativa y ritual, estas polaridades simétricas combaten entre sí, y una gana a la otra. Por ejemplo, un mito de Larráinzar narra cómo el apóstol San Andrés, patrón del pueblo, encontró el lugar actual del pueblo y fundó la iglesia (Ochiai 1981). El mito dice que San Andrés, después de haber buscado mucho, encontró un llano con una laguna. Le gustó el lugar y forzó al dueño de la laguna a salir de ahí. Aquí se observa una especie de competencia entre San Andrés que es el hermano del sol/Nuestro Dueño, y el dueño de la laguna llamado tzo$t z k$ 'ob ("Brazo Peludo"), que es una metamorfosis del Dueño de la Tierra. En esta competencia San Andrés venció a $t z o t z k$ 'ob y fundó el pueblo. El mito dice que tzotzk'ob no sabía hablar, lo cual simboliza su carácter pre-cultural relacionado con los seres del inframundo.

La colección de las tradiciones orales de Zinacantán, recopilada por Robert M. Laughlin, incluye dos textos en los que la gente de Chiapa de Corzo es llamada tzotzk'ob y se les atribuye haber robado una campana de la iglesia de Zinacantán (Laughlin 1977: $100-101,132-135)$. Aunque tzotzk'ob en estas narraciones no esté directamente caracterizado ni como el Dueño de la Tierra ni como un Demonio, tiene marcados rasgos periféricos tales como 'bajo' (Chiapa de Corzo=tierras bajas), 'desorden' (ladrones), 'naturaleza' ("Brazo Peludo"), todos los cuales pueden ser atributos demoniacos. Tales rasgos contrastan con los de centralidad desde el puntos de vista zinacanteco: 'alto' (Zinacantán $=$ tierras altas), 'orden' (sistema de cargos), y 'cultura' (iglesia), donde Nuestro Dueño y los Dioses Protectores los salvaguardan. Lo anterior sugiere que los relatos sobre $t z o t z k$ 'ob contienen esencialmente el tema de combate o competencia entre los Demonios y el sol/Nuestro Dueño.

Edmund Leach argumenta que si un mito se define como una expresión en palabras "dice" lo mismo que un ritual si éste se concibe como una expresión en acciones (Leach 1954: 13-14). Es precisamente durante el carnaval que el mismo patrón cosmológico, o sea, la competencia entre los principios sobrenaturales (sol/Nuestro Dueño vs. los Demonios), toma la forma de las acciones rituales. 
REVUELTA Y RENACIMIENTO ...

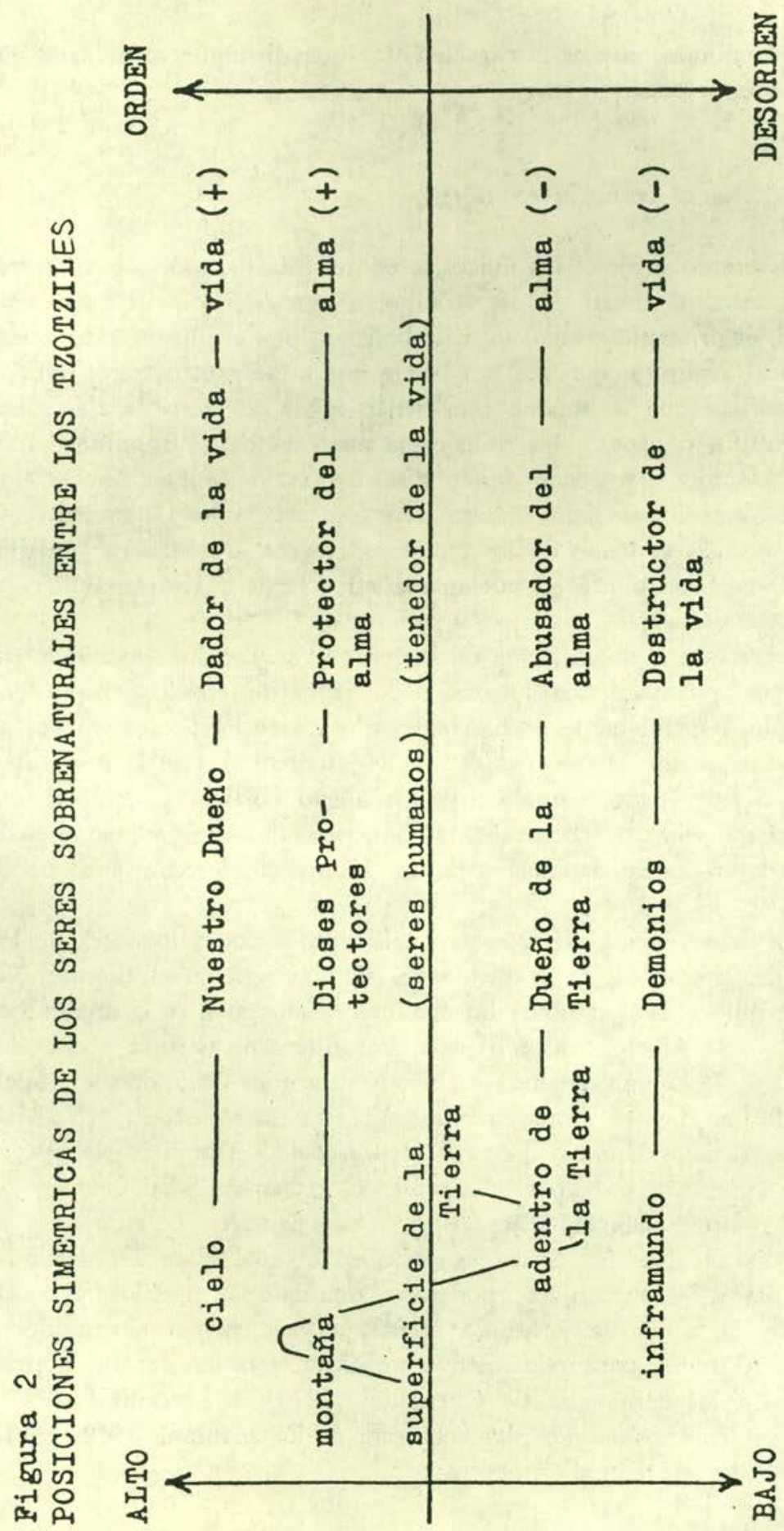

Estudios de Cultura Maya. Vol. XV, 1984

Instituto de Investigaciones Filológicas/

Centro de Estudios Mayas, UNAM

http://www.iifilologicas.unam.mx/estculmaya/ 
En mi opinión, esta es la característica que distingue al carnaval de las otras fiestas.

\section{Carnaval cosmológico tzotzil}

En sentido estricto, los únicos seres del inframundo que aparecen en el carnaval tzotzil son los Hombres Negros ( $j 7 i k^{\prime}$ aletik). Sin embargo, el principio cosmológico simbolizado por el inframundo actúa como un campo magnético tan fuerte que atrae a otros seres míticos e históricos que se supone que tienen algún atributo de desorden, pre-cultura o caos, y los transforma en seres del inframundo. Así, los personajes que tienen origen histórico, como prueba Bricker, los Lacandones, los soldados mexicanos y franceses, y los Guatemaltecos, etc., se vuelven socios de los Hombres Negros. De manera genérica denominaré de ahora en adelante a estos seres de inframundo y a sus trasmutaciones "extranjeros poderosos".

Parece que la imaginación de la gente se vuelve sumamente activa en el campo magnético del origen de los extranjeros poderosos. Por ejemplo, recientemente se han agregado varios elementos nuevos al uniforme de los Monos ( $\max$ ): anteojos oscuros, pantalones cortos de piel de venado y una varilla de hierro cortada y doblada que cuelga del cinturón como si fuera una espada. Aparentemente estos añadidos refuerzan la imagen de los Monos como extranjeros poderosos.

Los extranjeros poderosos son considerados como los seres de los días del pre-orden, antes de que el sol existiera en el mundo. No sólo temporal sino también espacialmente, su origen es la lejanía: el símbolo de su carácter periférico. Por ejemplo, en una noche del carnaval de Larráinzar, los Hombres Negros y los Capitanes se reúnen y cada uno dice de dónde viene: “¡Yo vine de México!”, “¡Yo vine de los Estados Unidos!". En 1979, uno de los Hombres Negros, al darse cuenta de que yo estaba presente, exclamó: “ $¡$ Yo vine de Japón!”, porque sabía que Japón es un país lejano.

El carnaval es un periodo caótico en el cual el orden diario se aniquila y los extranjeros poderosos dorninan al pueblo temporalmente. Se anula la jerarquía cotidiana y se revela el mundo al revés. Al revés, para relativizar y nulificar el orden central normativo. En los carnavales de Chenalhó (1978) y Larráinzar (1979, 1981) y en la fiesta de San Sebastián de Zinacantán (1979, 1981) observé los siguientes elementos: 
1. Imposición y confirmación del orden a través del sistema de cargo.

2. Introducción de elementos violentos y extraños a la vida cotidiana: carrera de caballos, peleas, carrera de oficiales de cargo por el pueblo, procesiones en dirección de las manecillas de reloj (lo cual es el sentido inverso de los movimientos rituales normales), obscenidades tales como capacidad sexual anormal, robo en la plaza, indiferencia hacia la iglesia, uso de español (que se considera pre-cultural por haber precedido al tzotzil) (Gossen 1974:181, 306; cf. Holland 1963: 72), uso de tambores que sólo se tocan durante estas fiestas (t'ent'en Zinacantán, bin en Chamula y Chenalhó). ${ }^{4}$

3. Cambio de identidad y parodias de lo cotidiano: de curaciones, de objetos sagrados tales como banderas de la iglesia; imitación grotesca de las autoridades del pueblo por los extranjeros poderosos.

4. La presentación de chivos expiatorios para luego castigarlos o ejecutarlos por tener mala conducta y por ser autoridades del pueblo.

En resumen, durante el carnaval los extranjeros poderosos, símbolos del principio opuesto al del sol/Nuestro Dueño, invaden el pueblo y nulifican el orden cotidiano establecido por el sol/Nuestro Dueño.

El carnaval tzotzil se celebra en un periodo de cinco días llamado cliayk'in, que se ha traducido convencionalmente como "los días perdidos". Estos cinco días se consideran de mala suerte. La gente prefiere quedarse en casa para evitar accidentes y encuentros con los seres del inframundo (Villa Rojas 1968: 149). En mi opinión, ch'ayk'in debería traducirse: "el sol perdido" o "el periodo sin sol", pues es el lapso en que se aniquilan temporalmente el orden normativo y la jerarquía social que están basados en el principio del sol/Nuestro Dueño, el cual está ausente. El sol desaparece y el

4 Vogt, al referirse a Rodney Needham (1967), discute que el tambor de tipo teponaztli, llamado t'ent'en en Zinacantán, induce una atmósfera de transición a la fiesta de San Sebastián (Vogt 1977:239). La hipótesis de Needham, sin embargo, se refiere al carácter catalizador del sonido fuerte percusivo que el t'ent'en no produce. El t'ent'en, al igual que el bin de Chamula y Chenalhó, se toca suavemente y suena más bien débil; como gotas de agua. Aunque Vogt esté en lo cierto al decir que la fiesta de San Sebastián es el festival del año nuevo o del cambio de tiempo en Zinacantán, el t'ent'en, a mi parecer, ocupa un papel integrante de la fiesta no por la cualidad de su sonido sino por su aparición única cada año en esta ocasión. Al ser su sonido así semióticamente marcado, el t'ent'en está estrechamente ligado a un cierto periodo, la fiesta de año nuevo. 
periodo de ch'ayk'in se considera como la noche prolongada en que los Demonios y sus transformaciones dominan al mundo como lo hacían en el pasado mítico. Es el periodo del retorno al tiempo primordial en que no había sol, ni luna, ni santos, ni orden; sólo existían Demonios, Judíos y Monos.

¿Qué encierra el artificio del retorno al estado primordial que destruye el sistema actual? Es importante notar que al presentar esta situación de manera teatral lógicamente destaca el significado del fin de este periodo cático y de resurgimiento del orden. La siguiente sinopsis de la tradición oral de Chamula, recogida por Gossen muestra la esencia de la estructura del carnaval, o sea, la introducción del caos destructivo en la nueva creación.

Hace mucho tiempo el sol desapareció por cinco días y la gente pensó que iba a morir... Cuando cayó la oscuridad, surgieron los Demonios, los leones, las serpientes, los jaguares: muchos murieron y fueron devorados por los Demonios... Cuando volvió a aparecer la luz, no había hombres sino sólo pájaros... Entonces vino Nuestro Padre para crear a otros hombres y los formó de barro (Gossen 1974: 322).

El carnaval tzotzil es un ritual de combate entre orden y desorden, cosmos y caos, regularidad e irregularidad. Ya que la fiesta dura sólo cinco días, los Demonios lógicamente son vencidos en el último, y el sol/Nuestro Dueño recupera el mando. Aunque los extranjeros poderosos se hayan retirado de la escena, no han sido muertos por el principio revitalizado; retienen su potencia periférica en el universo y cada año, durante el carnaval, resurgen del inframundo como principio opuesto al sol/Nuestro Dueño para causar el caos que renueva la sociedad.

No me parece que la celebración anual del carnaval esté basada en "la visión cíclica del tiempo" que engendra "la distorsión temporal" como infiere Bricker. Lo que piensa Kenneth Burke sobre la recurrencia de combate entre los principios opuestos en los mitos nos hará entender mejor y aclarará la estructura del carnaval tzotzil. Burke dice:

Mientras que la traducción mítica de la oposición en términos de competencia permite que las ideas, tales como orden y desorden, cosmos y caos, sean representadas por los competidores personificados quienes triunfan uno sobre otro, o se suceden uno detrás del otro, todavía queda el hecho de que cualquier sistema de orden implica el desorden correspondiente. La persis- 
tencia de las oposiciones lógicas, a pesar de las posibilidades de la victoria mítica, puede ser tratada mejor de las siguientes maneras: 1) por un mito según el cual, aunque uno de los competidores sea vencido (o, en los términos más perfectos, "muerto"), todavía sobrevive de algún modo... con la amenaza constante de que puede levantar una revuelta otra vez. 2) Por un mito según el cual el principio vencido periódicamente sucede al otro para reinar por una temporada y para ser reemplazado de nuevo, en forma periódica por el principio opuesto (Burke 1968: 395).

Burke dice que en la dialéctica del mito de combate "tal oposición puede ser traducida más bien en términos de cooperación; ambas fuerzas y principios son necesarios para formar el mundo, por lo cual el principio de 'desorden' se hace, por sí, una especie de orden también" (Burke 1968: 395). La primera de las dos versiones de Burke se da cuando un lado vence al otro pero no ouede asegurar su victoria. Mientras tanto, "la periodicidad de estaciones nos proporciona la imagen básica para la segunda verrión, la cual traduce el principio de oposición en términos de sucesión cíclica" (Burke 1968: 395). Dicho de otra manera, para ritualizar las transiciones de estaciones de manera más efectiva, los mitos y rituales de "combate" nos ofrecen el modelo más eficaz para organizar los símbolos concernientes (Yamaguchi 1975: 46).

La segunda versión de Burke nos irteresa principalmente porque el cambio de estación está más estrechamente ligado al carnaval tzotzil, que es esencialmente una ceremonia de renovación del tiempo. El ritual de uayeb, la versión yucateca de ch'ayk'in, era una ceremonia del año nuevo en el siglo xvi (Coe 1965: 99-103; Tozzer 1941: 138-139), aunque se celebraba en julio. La noticia data de 1553 cuando Diego de Landa se enteró del ritual (Tozzer 1941: $150)$. Bricker calculó recientemente que uayeb correspondía originalmente al solsticio invernal (Bricker 1982), lo cual tiene sentido pues corresponde a la época del comienzo del nuevo año solar. Según Landa, el ritual de uayeb tenía los siguientes aspectos: 1) los hombres corrían descalzos sobre carbón al rojo vivo; 2) los cinco días de uayeb implicaban mala suerte; 3 ) después de uayeb venía el año nuevo. Si recordamos que en el carnaval de Chamula se observa hoy en día el ritual de la carrera sobre el zacate ardiente, estos elementos del rito de uayeb parecen ser paralelos al carnaval tzotzil contemporáneo. La misma idea tomó forma literaria en el Popol Vuh (Recinos 1947), donde la conquista de Xibalbá, el inframundo, por los héroes culturales (Hunahpú e Ixba- 
lanqué) se narra de la siguiente manera: 1) los héroes saltan sobre la fogata, 2) los héroes mueren una vez durante el periodo de cinco días en el cual los seres del inframundo festejan, pero 3) los héroes renacen como jóvenes bellos y vencen al inframundo. Podríamos concluir que la muerte temporal de los héroes en el Popol Vuh, el ritual de uayeb y el carnaval tzotzil comparten una estructura; es decir, a través de la invasión temporal del caos primordial, el tiempo, contaminado y debilitado a través de su transcurso, se renueva y renace. No sobraría añadir que este modelo teatral no sólo se observa entre los tzotziles, sino también en las fiestas follklóricas de Europa y Japón.

Durante los carnavales tzotziles, hay algunos chivos expiatorios. Guajolotes y gallos son sacrificados por los Demonios y éstos ridiculizan y públicamente se burlan de las autoridades del pueblo. Los Demonios, o desorden, castigan y revitalizan al orden social que se ha contaminado y debilitado en el año que ha pasado. Así, la estación vieja que debe marcharse es expulsada más allá del límite de la comunidad y lleva consigo toda la impureza acumulada en la sociedad (Yamaguchi 1975: 46). El principio del sol/Nuestro Dueño, que había muerto o desaparecido, ahora rejuvenece y los Demonios se retiran a la oscuridad de la noche, al inframundo y a la periferia del sistema de valor. De esta manera, los Demonios, a quienes llamamos en la Figura 2 "destructores de la vida", desempeñan el papel de "renovadores de la vida" durante el carnaval, y Nuestro Dueño, que es el "dador de la vida" diaria, se vuelve "resucitado de la vida". Tal es en esencia, la naturaleza invertida del carnaval tzotzil.

Quisiera concluir que los tzotziles tienen como modelo cosmológico la relación opuesta y cooperativa entre los principios de cielo e inframundo; no hay otra fiesta en la cual este modelo se ritualice más íntegramente que el carnaval. En este sentido, podríamos llamar al carnaval la fiesta tzotzil cosmológica por excelencia.

Octavio Paz dice: "La Fiesta es una Revuelta, en el sentido literal de la palabra" (Paz 1972:46). El carnaval tzotzil lo comprueba porque es un ritual para re-volver al estado primordial mítico; para renacer y reempezar de ahí. Si la función fundamental de la fiesta es activar la vida diaria, el carnaval es el que revive de manera fundamental la vida y el tiempo. Quisiera terminar este ensayo con una cita de El Laberinto de la Soledad de $\mathrm{Paz}$, en que la palabra "fiesta" podrá ser equiparada con "carnaval": 
La Fiesta es una operación cósmica: la experiencia del Desorden, la reunión de los elementos y principios contrarios para provocar el renacimiento de la vida. La muerte ritual suscita renacer... La fiesta es un regreso a un estado remoto e indiferenciado, prenatal o presocial, por decirlo así. Regreso que es un comienzo, según quiere la dialéctica inherente a los hechos sociales ( $\mathrm{Paz}$ 1972: 46).

\section{BIBLIOGRAFIA}

BAKHTIN, M.

1967 Rabelais and his World. MIT Press, Cambridge.

Becquelin-Monod, Aurore y Alain Breton

1973 "Le carnaval de Bachajón". Journal de la Societé des Américanistes $65: 89-103$.

1979 "El carnaval de Bachajón. Cultura y naturaleza: dinámica de un ritual tzeltal", Estudios de Cultura Maya XII: 191-239.

Blaffer, Sarah C.

1972 The Black-man of Zinacantán: a Central American Legend. University of Texas Press, Austin.

BRICKER, Victoria R.

1973 Ritual Humor in Highland Chiapas. University of Texas Press, Austin.

1981 The Indian Christ, the Indian King: The Hisiorical Substrate of Maya Myth and Ritual. University of Texas Press, Austin.

BURKE, KENNETH "The Origin of the Maya Solar Calendar". Current Anthro-

1982 "The Origin of the

1968 "Myth, Poetry, and Philosophy". En Language as Symbolic Action: Essays on Life, Literature, and Method. University of Coe, Michael D. California Press, Berkeley \& Los Angeles.

1965 "A Model of Ancient Community Structure in the Maya Lowlands", Sauthwestern Journal of Anthropology, 21(2):97-114.

DE Vos, JAN

1979 La paz de Dios y del rey. La Conquista de la selva lacandona 1821-1810. Colección Ceiba 8, Gobierno del Estado de Chiapas, FONAPAS, Tuxtla Gutiérrez.

Gossen, GARY H.

1974 Chamulas in the World of the Sun: Time and Space in a Maya Oral Tradition. Harvard University Press, Cambridge.

1975 "Animal Souls and Human Destiny in Chamula". Man $10: 448-461$.

Guiteras Holmes, Calixta

1946 Informe de San Pedro Chenalhó. Manuscrito microfilmado. Universidad de Chicago, Chicago.

1961 Perils of the Soul. Free Press, Glencoe.

Holland, WHLLiam R.

1963 Medicina maya en los altos de Chiapas: un estudio-del cambio socio-cultural. Instituto Nacional Indigenista, México. 
LAUGHLIN, ROBERT M.

1977 Of Cabbages and Kings: Tales from Zinacantán. Smithsonian Contributions to Anthropology 23, Smithsonian Institution,

Leach, EDMund Washington, D.C.

1954 Political Systems of Highland Burma: A Study of Kachin Social Structure. London School of Economics and Political Science, London.

Medina Andrés

1965 El carnaval de Tenejapa. Anales del INAH, XVII (1964: 323-

NEEDHAM, RODNEY 341. Instituto Nacional de Antropología e Historia. México.

Oahiar, Kazuyasu

"Percussion and Transition". Man 2:606-614.

1981 Mekishiko nanbu Tzotzil-goken koto-densho ni okeru katorikku-seijin no iso ( $\mathrm{La}$ esfera de los santos católicos en una tradición oral tzotzil de México meridional). En: Nobukiyo Nomura, ed., Nambu mekishiko sonraku ni okure katorikkukei bunka no kenkyu (Estudios de la cultura católica en los pueblos de México meridional), pp. 261-287, Universidad de Kyushu, Fukuoka, Japón.

Ochiar, Kazuyasu e Inés Sanmiguel

1981 "Moch: el espacio simbólico de la arquitectura ceremonial entre los Tzotziles de los altos de Chiapas". Ponencia presentada a la XVII Mesa Redonda de la Sociedad Mexicana de Antro-

Paz, Octavio pologia. San Cristóbal de Las Casas, Chiapas, junio 21-27.

1972 El laberinto de la soledad. Colección Popular 197, Fondo de Pozas, Ricardo Cultura Económica, México. (Primera edición 1950).

1959 Chamula: un pueblo indio de los altos de Chiapas. Memorias, 8, Instituto Nacional Indigenista, México.

Recinos, Adrián

1947 Popol Vuh, las antiguas historias del Quiché. Fondo de Cultura Económica, México.

TOZzer, ALFred M.

1941 "Landa's Relación de las cosas de Yucatán". Papers of the Peabody Museum of American Archaeology and Ethnology, 18, Harvard University, Cambridge.

Vilia Rojas, Alfonso

1968 "Los conceptos de espacio y tiempo entre los grupos mayanses contemporáneos". En: Miguel León-Portilla, Tiempo y realidad en el pensamiento maya: ensayo de acercamiento. $\mathrm{pp}$. 119-167. Instituto de Investigaciones Históricas, Universidad Voot, Evon Z. Nacional Autónoma de México, México.

1969 Zinacantán: A May Community in the Highlands of Chiapas. The Belknap Press of Harvard University Press, Cambridge.

1970 "Human Souls and Animal Spirits in Zinacantán". En: Jean \& Pierre Maranda, eds., Echanges et communications: mélanges offerts a Claude Lévi-Strauss d̀ son 60ème anniversaire, pp. 1148-1167. Mouton Publishers, The Hague.

1976a "Rituals of Reversal as a Means of Rewiring Social Structure". En: Agehananda Bharati, ed., The Realm of the Extra- 
Human: Ideas and Actions, pp. 201-212, Mouton Publishers, The Hague.

1976b Tortillas for the Gods: A Symbolic Analysis of Zinacanteco Rituals. Harvard University Press, Cambridge.

1977 "On the Symbolic Meaning of Percussion in Zinacanteco Ritual." Journal of Anthropological Research 33(3):231-244.

YAMAGUCHI

1975 Bunka to ryogisei (Cultura y ambigüedad). Editorial Iwanami Shoten, Tokio, Japón. 